\title{
Synthesis and Biological Activity of Peptide $\alpha$-Ketoamide Derivatives as Proteasome Inhibitors
}

\author{
Salvatore Pacifico, ${ }^{\dagger}$ Valeria Ferretti, ${ }^{\dagger}$ Valentina Albanese, ${ }^{\dagger}$ Anna Fantinati, ${ }^{\dagger}$ Eleonora Gallerani, ${ }^{\dagger}$ \\ Francesco Nicoli, ${ }^{\dagger}$ Riccardo Gavioli, ${ }^{\dagger}$ Francesco Zamberlan, ${ }^{\dagger}$ Delia Preti, ${ }^{*}{ }^{\dagger}$ (i) and Mauro Marastoni ${ }^{\dagger}$ \\ ${ }^{\dagger}$ Department of Chemical and Pharmaceutical Sciences, University of Ferrara, Via Luigi Borsari 46, 44121 Ferrara, Italy \\ ${ }^{\ddagger}$ School of Chemistry, University of Nottingham, University Park, NG7 2RD, United Kingdom
}

Supporting Information

\begin{abstract}
Proteasome activity affects cell cycle progression as well as the immune response, and it is largely recognized as an attractive pharmacological target for potential therapies against several diseases. Herein we present the synthesis of a series of pseudodi/tripeptides bearing at the Cterminal position different $\alpha$-ketoamide moieties as pharmacophoric units for the interaction with the catalytic threonine residue that sustains the proteolytic action of the proteasome. Among these, we identified the 1-naphthyl derivative 13c as a potent and selective inhibitor of the $\beta 5$ subunit of the $20 \mathrm{~S}$ proteasome, exhibiting nanomolar potency in vitro $\left(\beta 5 \mathrm{IC}_{50}=7 \mathrm{nM}, \beta 1 \mathrm{IC}_{50}=60 \mu \mathrm{M}, \beta 2 \mathrm{IC}_{50}>100 \mu \mathrm{M}\right)$. Furthermore, it significantly inhibited proliferation and induced apoptosis of the human colorectal carcinoma cell line HCT116.
\end{abstract}

KEYWORDS: Proteasome, pseudopeptides, $\alpha$-ketoamides, $\beta$ subunits inhibition

$\mathrm{T}$ he $26 \mathrm{~S}$ proteasome is a sophisticated multicatalytic enzymatic complex of key importance for intracellular protein degradation and homeostasis in eukaryotic organisms. ${ }^{1,2}$ It appears as a hollow cylinder consisting of a central $20 \mathrm{~S}$ proteolytic core (CP) capped by two $19 \mathrm{~S}$ regulatory particles, which are responsible for the recognition of polyubiquitinated substrates and their guiding and transport within the CP. ${ }^{3}$ The $20 \mathrm{~S}$ proteasome is formed by four stacked heptameric rings of $\alpha$ - and $\beta$-type subunits with the typical stoichiometry $\alpha_{7} \beta_{7} \beta_{7} \alpha_{7}$. In eukaryotic cells, each $\beta$ ring hosts three catalytic active sites with distinct proteolytic specificity: the $\beta 1$ subunit promotes the so-called caspase-like (C-L) or post acidic (PGPH) activity responsible for the processing of the substrates after acid residues; the $\beta 2$ subunit displays the trypsin-like (T-L) activity with hydrolysis after basic residues; the $\beta 5$ subunit undertakes the chymotrypsin-like activity (ChT-L), cutting substrates after hydrophobic and aromatic residues. Despite the different specificity, the three active sites share a common catalytic mechanism that involves a key $\mathrm{N}$ terminal threonine residue $\left(\mathrm{Thr}^{1}\right)$ responsible for the nucleophilic attack at the specific peptide bond of the substrate. ${ }^{4,5}$

Proteasome activity affects cell cycle progression as well as the immune response, and it is largely recognized as a very attractive pharmacological target for potential therapies against a series of diseases. ${ }^{6,7}$ In particular, several classes of both specific and nonspecific inhibitors of proteasome activity have been developed. ${ }^{7-9}$ The translational potential of this system has been well established in cancer therapy with the clinical success of the three proteasome inhibitors bortezomib, carfilzomib, and ixazomib approved for the treatment of hematological malignancies such as multiple myeloma. ${ }^{10-14}$ Nonetheless, despite the efficacy of these drugs, several limitations in their clinical employment have emerged. ${ }^{15}$ In particular, a percentage of patients does not respond to the treatment and a high relapsing frequency has been observed, probably due to the development of resistances over time. In addition, dose-limiting toxicity has been witnessed after administration of proteasome inhibitors currently in use. Peripheral neuropathy is one of the most recurrent side effects which has been attributed to off-target interactions. ${ }^{15}$ Thus, the design of a new generation of inhibitors with high selectivity for the active site of the target enzyme continues to be an active field of research since it could overcome some of the typical side effects described for the first generation of drugs. $8,15,16$

In this context, our research efforts have been aimed at the design, synthesis, and biological characterization of new classes of peptides able to inhibit the proteasome activity. ${ }^{17-21}$ Each of these is characterized by a distinct pharmacophoric unit, consisting of different electrophilic groups potentially able to interact with the hydroxyl group of the side chain of the $\mathrm{Thr}^{1}$ residue of the enzyme responsible for the proteolytic action. Herein, we present a new contribution in this field consisting of the development of a series of peptide-based derivatives bearing at the $\mathrm{C}$-terminal residue an $\alpha$-ketoamide pharmacophoric unit as the electrophilic substrate. This moiety has

Received: May 24, 2019

Accepted: June 6, 2019

Published: June 6, 2019 
already been successfully introduced into the structure of various pseudopeptidic enzyme inhibitors. ${ }^{22,23}$ Of note, some examples of proteasome inhibitors bearing an $\alpha$-ketoamide function have also been reported in the literature, such as the cyclic polypeptide TMC-95A and its diastereoisomers TMC95B-D. ${ }^{24,25}$ Moreover, this electrophilic function has been inserted in the backbone of linear peptides targeting the proteasome. ${ }^{26}$ According to these and more recent studies, the $\alpha$-ketoamide motif is emerging as the most promising group with a possible therapeutic application against the proteasome because of its ability to induce a potent but reversible inhibition of the enzyme's activity if compared to other investigated $\mathrm{C}$-terminus warheads (i.e., $\alpha$-ketoaldehyde, $\alpha, \beta$ epoxy ketone, boronic acid, vinyl sulfone). ${ }^{27,28}$ Thus, we focused our attention on the trileucine derivative 1a (shown in Figure 1) that has been previously reported to inhibit the

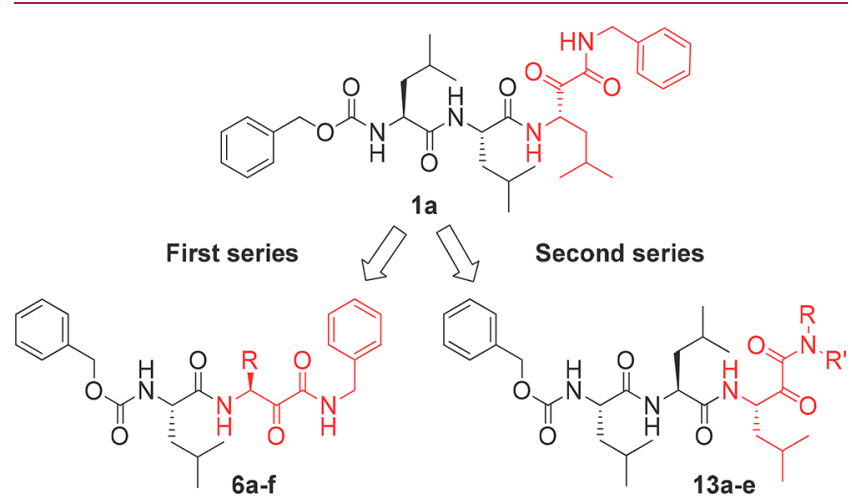

Figure 1. New $\alpha$-ketoamide peptide derivatives as potential proteasome inhibitors.

proteasome catalytic subunits at nanomolar concentrations, ${ }^{29}$ and with the above evidence in mind, we designed two series of derivatives modeled on its structure, as depicted in Figure 1.

The first series $(\mathbf{6 a - 6 f})$ was conceived with the aim of simplifying the tripeptide structure of $\mathbf{1 a}$ to shorter dipeptide analogues in which the $\alpha$-keto benzylamide pharmacophoric unit of the parent compound was maintained but combined with different $\mathrm{C}$-terminal residues. In the second series (13a$13 \mathbf{e})$, the trileucine sequence of $\mathbf{1 a}$ was functionalized with different $\alpha$-keto (cyclo)alkyl/(hetero)arylamides. A novel convergent synthetic approach has been designed and applied for the obtainment of the latter derivatives. The available strategies for the synthesis of $\alpha$-ketoamide derivatives were recently described in an exhaustive review. ${ }^{25}$ The synthesis of the first series of target dipeptides $(\mathbf{6 a}-\mathbf{6 f})$ was performed as depicted in Scheme 1 and in analogy to procedures previously reported by Stein et al. ${ }^{27}$ Briefly, different Fmoc protected L- $\alpha$ amino acids $(\mathbf{2} \mathbf{a}-\mathbf{2} \mathbf{f})$ were initially converted into the respective aldehydes $(\mathbf{3 a - 3 f})$ by a known two-step method reported by Fehrentz and Castro. ${ }^{30}$ This was based on the initial conversion of $\mathbf{2 a - 2 f}$ into the corresponding $\mathrm{N}, \mathrm{O}$ dimethyl hydroxamates via activation of the carboxyl group with 1-ethyl-3-(3-(dimethylamino)propyl)-carbodiimmide (WSC) and $N$-hydroxybenzotriazole (HOBt) and subsequent treatment with $\mathrm{N}, \mathrm{O}$-dimethylhydroxylamine. In the next step, the hydroxamate derivatives were efficiently reduced to the corresponding aldehydes $\mathbf{3 a}-\mathbf{3 f}$ with $\mathrm{LiAlH}_{4}$. These were then treated with benzyl isocyanide in the presence of acetic acid according to the multicomponent Passerini reaction. The resulting $\mathrm{N}$-Fmoc-O-acetyl hydroxyamide intermediates were
Scheme 1. Synthesis of the First Series of Ketoamide Dipeptide Derivatives ${ }^{a}$

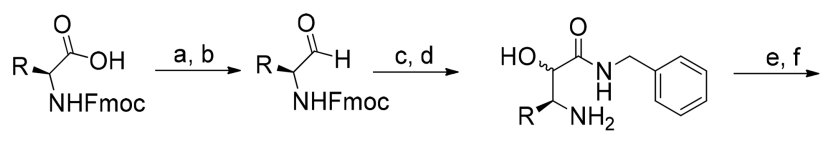

\begin{tabular}{|c|c|c|}
\hline $\begin{array}{l}\text { 2a } R=\text { Benzyl } \\
\text { 2b } R=4 \text {-(tert-butoxy)Bn } \\
\text { 2c R=1-Naphthyl } \\
\text { 2d R= } \mathrm{CH}_{2} \text { CONHTrt } \\
\text { 2e R= Isopropyl }\end{array}$ & $\begin{array}{l}\text { 3a } \mathrm{R}=\text { Benzyl } \\
\text { 3b } \mathrm{R}=\text { 4-(tert-butoxy)Bn } \\
\text { 3c } \mathrm{R}=1 \text {-Naphthyl } \\
\text { 3d R= } \mathrm{CH}_{2} \text { CONHTrt } \\
\text { 3e } \mathrm{R}=\text { |sopropyl } \\
\text { 3f } \mathrm{R}=\text { Isobutyl }\end{array}$ & $\begin{array}{l}\text { 4a } R=\text { Benzyl } \\
\text { 4b } R=4 \text {-(tert-butoxy)Bn } \\
\text { 4c } R=1-N a p h t h y \mid \\
\text { 4d } R=\mathrm{CH}_{2} \text { CONHTrt } \\
\text { 4e } R=\mid \text { sopropyl } \\
\text { 4f } R=\text { Isobutyl }\end{array}$ \\
\hline
\end{tabular}

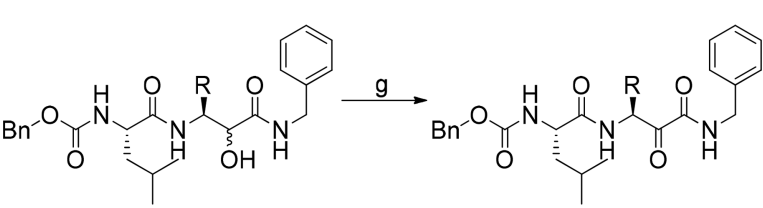

$$
\begin{array}{ll}
\text { 5a } & R=\text { Benzyl } \\
\text { 5b } & R=4-H_{y d r o x y} \text { benzyl } \\
\text { 5c } & R=1-N_{a p h t h y l} \\
\text { 5d } & R=\mathrm{CH}_{2} \mathrm{CONH}_{2} \\
\text { 5e } & \mathrm{R}=\text { Isopropyl }
\end{array}
$$$$
\text { 5f } \mathrm{R}=\text { |sobutyl }
$$

$$
\begin{array}{ll}
\text { 6a } & R=\text { Benzyl } \\
\text { 6b } & R=4-\text { Hydroxy benzyl } \\
\text { 6c } & R=1-\text { Naphthyl } \\
\text { 6d } & R=\mathrm{CH}_{2} \mathrm{CONH}_{2} \\
\text { 6e } & \mathrm{R}=\mid \text { sopropyl } \\
\text { 6f } & \mathrm{R}=\text { Isobutyl }
\end{array}
$$

${ }^{a}$ Reagents and conditions: (a) N,O-Dimethylhydroxylamine hydrochloride, WSC, $\mathrm{HOBt}, \mathrm{Et}_{3} \mathrm{~N}, \mathrm{DMF}$; (b) $\mathrm{LiAlH}_{4}$, THF; (c) benzyl Isocyanide, $\mathrm{CH}_{3} \mathrm{COOH}$; (d) $\mathrm{LiOH}$, THF/MeOH; (e) Z-Leu-OH, WSC, HOBt, DMF; (f) TFA (for $\mathbf{5 b}$ and $\mathbf{5 d}$ ); and (g) 2iodoxybenzoic acid, DMSO.

fully deprotected with a mild basic treatment to furnish derivatives $\mathbf{4 a}-\mathbf{4 f}$. The desired $\alpha$-hydroxyamides $\mathbf{5 a}-\mathbf{5 f}$ were then obtained as inseparable diastereomeric mixtures by standard coupling with Z-Leu-OH followed by side chain deprotection with TFA when necessary ( $5 \mathbf{b}$ and $\mathbf{5 d}$ ). Finally, the oxidation with 2 -iodoxybenzoic acid gave the ketoamides $6 a-6 f$.

For the synthesis of the second series of tripeptide analogues $13 \mathrm{a}-13 \mathrm{e}$, in which the nitrogen atom of the $\alpha$-ketoamide group was substituted with different (cyclo)alkyl/(hetero)aryl moieties, we designed the alternative synthetic pathway reported in Scheme 2. This novel approach has the advantage of not requiring the use of isocyanides that are in some cases toxic and mostly characterized by a well-known aggressive and extremely unpleasant smell. First, Boc-protected leucinal 7 was reacted with vinylmagnesium bromide to give the vinyl derivative $\mathbf{8}$ as a diastereomeric mixture. ${ }^{31}$ The following protection with 2,2-dimethoxypropane led to a mixture of cistrans oxazolidine 9, whose double bond was oxidized with $\mathrm{RuO}_{2}$ and $\mathrm{NaIO}_{4}$.

The resulting carboxylic intermediate $\mathbf{1 0}$ was coupled with different amines in the presence of HATU and DIPEA. The subsequent deprotection with trifluoroacetic acid gave 11a11 e as diastereomeric mixtures. These were then coupled under standard conditions with the N-protected dipeptide ZLeu-Leu-OH to give the $\alpha$-hydroxyamides $12 \mathrm{a}-12 \mathrm{e}$ that were successively oxidized to the corresponding $\alpha$-ketoamides 13a13e with 2 -iodoxybenzoic acid. The $\alpha$-hydroxyamides $5 \mathbf{a}-\mathbf{5 f} /$ $12 \mathrm{a}-12 \mathrm{e}$ and the $\alpha$-ketoamides $6 \mathrm{a}-6 \mathrm{f} / 13 \mathrm{a}-13 \mathrm{e}$ were purified via preparative HPLC and characterized by ESI-MS and ${ }^{1} \mathrm{H}$ NMR spectroscopy.

The capability of the synthesized compounds of inhibiting each of the three proteasome activities was measured through an in vitro assay which is based on the employment of Suc- 
Scheme 2. Synthesis of the Second Series of Ketoamide Tripeptide Derivatives ${ }^{a}$
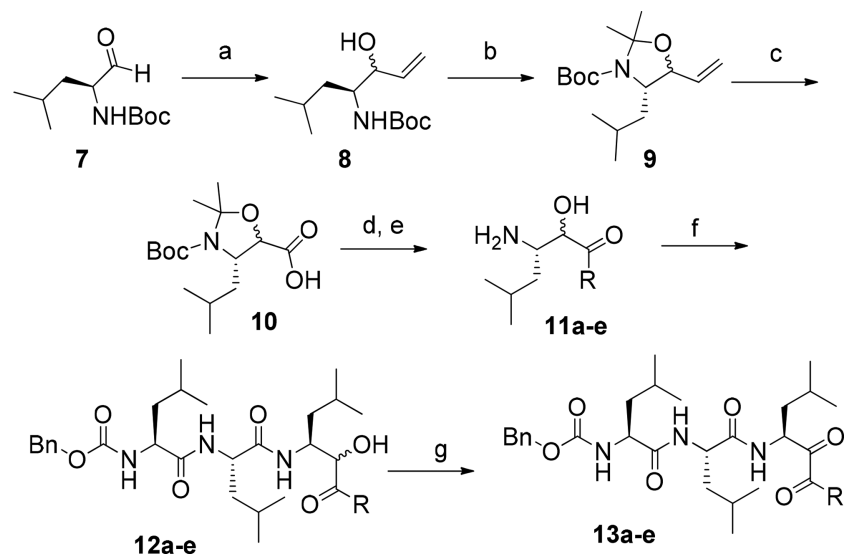

${ }^{a}$ Reagents and conditions: (a) vinylmagnesium bromide, $\mathrm{CH}_{2} \mathrm{Cl}_{2}$; (b) p-toluensulfonic acid, 2,2-dimethoxypropane, $\mathrm{CH}_{2} \mathrm{Cl}_{2} ;$ (c) $\mathrm{NaIO}_{4}$, ruthenium(IV) oxide hydrate, acetone; (d) appropriate amines $\mathbf{a}-\mathbf{e}$, HATU, DIPEA, DMF; (e) TFA; (f) Z-Leu-Leu-OH, HATU, DIPEA, DMF; (g) 2-iodoxybenzoic acid, DMSO; 11-13a R = 4-fluorobenzyl$\mathrm{NH}$; 11-13b R = morpholin-4-yl; 11-13c R = 1-naphthyl-NH; 1113d R = isobutyl-NH; 11-13e R = tetrahydroisoquinolin-2-yl.

LLVY-AMC (for the ChT-L), Boc-LRR-AMC (for the T-L), and Z-LLE-AMC (for the PGPH) as specific fluorogenic substrates. ${ }^{32}$ Briefly, semipurified proteasomes were pretreated with increasing concentrations $(0.01-100 \mu \mathrm{M})$ of the new pseudopeptides (5a-5f, 6a-6f, 12a-12e, and 13a-13e) in an activity buffer. The trileucine derivatives $\mathbf{1 a}$ and $\mathbf{1 b}$ (Table 1 , synthesized according to reported procedures ${ }^{28,29}$ ) have been evaluated under the same conditions for comparative reasons along with the known proteasome inhibitor MG132 (Z-LLL$\mathrm{CHO})^{33}$ as an internal standard. The inhibitory activity of all compounds is reported in Table 1 and expressed as $\mathrm{IC}_{50}$ values in micromolar concentrations.

The effects of $\mathbf{5 a}-\mathbf{5 f}$ and $\mathbf{1 2 a}-\mathbf{1 2} e$ against the three catalytic activities of proteasomes were evaluated in order to establish the actual importance of the ketone's carbonyl of the $\alpha$ ketoamide pharmacophore in the interaction with $\mathrm{Thr}^{1}$. It has been reported that such interaction leads to a reversible hemiacetal adduct resulting from the nucleophilic attack of the $\mathrm{Thr}^{1}$ hydroxyl group on the ketone carbonyl of the $\alpha$ ketoamide portion. ${ }^{28}$ Interestingly, although devoid of electrophilic properties, the $\alpha$-hydroxyamide moiety of $\mathbf{5 a - 5 f}$ and 12a-12e mimics the tetrahedral intermediate which is supposed to follow the nucleophilic addition of $\mathrm{Thr}^{1}$ to the $\alpha$-ketoamide. However, our SAR study strongly confirms that the presence of the electrophilic $\alpha$-ketoamide moiety is mandatory for the inhibitory activity toward all three catalytic sites as its conversion to the corresponding $\alpha$-hydroxyamide led to a marked loss of potency (compare $\mathbf{1 a}$ with $\mathbf{1 b}, \mathbf{5 a}-\mathbf{5 f}$ with 6a-6f, and 12a-12e with 13a-13e). Likewise, shortening of the trileucine motif of $1 \mathrm{a}$ to the dileucine analogue $6 f$ resulted in a general decrease of potency, particularly evident against the chymotryptic-like activity $\left(\beta 5 \mathrm{IC}_{50}=0.014\right.$ and $0.92 \mathrm{nM}$ for $1 \mathrm{a}$ and $\mathbf{6 f}$, respectively). Nonetheless, we explored the possibility of restoring the activity with the introduction of C-terminal amino acids other than the leucine residue of $6 \mathrm{f}$ (i.e., Phe, Tyr, 1-Nal, Asn, and Val for compounds 6a-6e, respectively). This led to a further reduction of potency with $\mathrm{IC}_{50}$ values that reached the high micromolar range against the three investigated activities. Thus, compound of (with the sequence Z-Leu-Leu-CONHBn) was confirmed as the most active of this first series as able to inhibit the three activities of the enzyme complex with $\mathrm{IC}_{50}$ values of about $1 \mu \mathrm{M}$, without significant selectivity in the biological response. Most of the analyzed dipeptide derivatives had a mild selectivity for the postacidic and/or chymotryptic activities, with the exception of 6e, characterized by a C-terminal valine, that inhibited the $\beta 2$ tryptic subunit $\left(\mathrm{IC}_{50}=2.11 \mu \mathrm{M}\right)$ with significant selectivity over the $\beta 1$ (7-fold) and $\beta 5$ (30-fold) subunits. These preliminary results suggested that both the length of the peptide sequence and the C-terminal leucine residue would contribute in eliciting a better inhibition. Thus, we designed the second series of tripeptide $\alpha$-ketoamides (compounds 13a-13e in Table 1) in which the Z-LLL template of 1a was maintained but combined with different substituents on the nitrogen of the $\alpha$-ketoamide moiety. The resulting compounds exhibited from submicromolar to low nanomolar potency in inhibiting the $\beta 5$ chymotryptic activity $\left(\beta 5 \mathrm{IC}_{50}\right.$ ranging from 7 to $770 \mathrm{nM}$ ), with various levels of selectivity over the $\beta 1$ and $\beta 2$ subunits. Among these, derivative 13c, in which the $\alpha$-keto benzylamide of 1 a was replaced by the 1-naphthylamide moiety, displayed the highest potency with an $\mathrm{IC}_{50}$ value of 7 $\mathrm{nM}$ against the chymotryptic activity and very low or no activity against the $\beta 1$ and $\beta 2$ subunits ( $\mathrm{IC}_{50}$ values of 57 and $>100 \mu \mathrm{M}$, respectively). Thus, the introduction of a bulky and lipophilic aromatic bicycle at the C-terminal portion of the linear peptide structure led to a slight improvement of the $\beta 5$ activity inhibition (2-fold) associated with a remarkable increase of selectivity (selectivity ratios: $\beta 1 / \beta 5=8.200, \beta 2$ / $\beta 5>14.200)$ in comparison with the parent compound 1a. In this series of molecules, the investigated ketoamide substitutions determined the following order of potency: 1naphthyl-NH > isobutyl-NH $\approx \mathrm{Bn}-\mathrm{NH}>$ 4-F-benzyl-NH > morpholin-4-yl > tetrahydroisoquinolin-2-yl. These data would suggest that the presence of a more flexible primary amide, compared to a secondary one, would enhance the inhibition of the ChT-L activity. This is particularly evident when comparing the activities of $1 \mathrm{a}$ and $13 \mathrm{e}$, since the latter's isoquinoline derivative can be considered a constrained analogue of the parent benzylamide compound.

The antiproliferative activity of selected compounds $(\mathbf{6 b}, \mathbf{6 f}$, 1a, 13a, 13c, and 13d) was evaluated at concentrations ranging from 0.1 to $100 \mu \mathrm{M}$ against the human colorectal carcinoma cell line HCT116 and compared to that of the reference inhibitor MG132. The effect of the compounds on cell viability was measured at $72 \mathrm{~h}$ and reported in Table 1 expressed as $\mathrm{IC}_{50}$. Interestingly, a significant antiproliferative activity was observed for all the examined molecules with variable degrees of potencies, basically reflecting their capability to inhibit the $\beta 5$ subunit of the proteasome, mediating the chymotryptic activity (ChT-L). Indeed, the Leu-Leu derivative 6 f $\left(\mathrm{IC}_{50}\right.$ ChT-L $=920 \mathrm{nM}$ and $\mathrm{IC}_{50}$ proliferation $=8.6 \mu \mathrm{M}$, Table 1) seems to be more potent than the Leu-Tyr analogue $6 \mathrm{~b}\left(\mathrm{IC}_{50}\right.$ ChT-L $=12.43 \mu \mathrm{M}$ and $\mathrm{IC}_{50}$ proliferation $>100 \mu \mathrm{M}$ ), while both compounds were shown to have lower activity than the reference pseudotripeptide 1a $\left(\mathrm{IC}_{50} \mathrm{ChT}-\mathrm{L}=14 \mathrm{nM}\right.$ and $\mathrm{IC}_{50}$ proliferation $=0.78 \mu \mathrm{M})$ and $\mathrm{MG} 132\left(\mathrm{IC}_{50} \mathrm{ChT}-\mathrm{L}=7 \mathrm{nM}\right.$ and $\mathrm{IC}_{50}$ proliferation $\left.=0.82 \mu \mathrm{M}\right)$. Notably, the tripeptide analogues 13a, 13c, and 13d, which all showed an $\mathrm{IC}_{50}$ for ChT-L $<100 \mathrm{nM}$, induced a strong antiproliferative effect, comparable or even superior to that of the reference pseudotripeptide $1 \mathrm{a}$ and of MG132, as all the three 
Table 1. Inhibition of the Proteasome Subunits by $\alpha$-Hydroxy/Ketoamide Peptides and Their Effect on Cell Proliferation (The Values Reported Are the Mean \pm SEM of Three Independent Experiments)

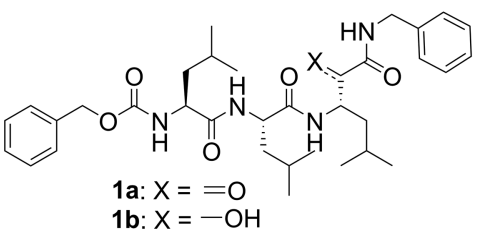

$\mathrm{R}$

cmpd $\quad \mathrm{R} \quad \mathrm{IC}_{50}$

MG132

$1 \mathrm{a}$

$1 b$

Dipeptide Analogues

5a $\quad \mathrm{Bn}$

6a $\mathrm{Bn}$

5b 4-OH-Bn

$6 b$ 4-OH-Bn

5c 1-naphthyl

6c 1-naphthyl

5d $\mathrm{CH}_{2} \mathrm{CONH}_{2}$

6d $\mathrm{CH}_{2} \mathrm{CONH}_{2}$

5e isopropyl

6e isopropyl

5f isobutyl

6f isobutyl

Tripeptide Analogues

12a 4-F-Bn-NH-

13a 4-F-Bn-NH-

12b morpholin-4-yl

13b morpholin-4-yl

12c 1-naphthyl-NH

13c 1-naphthyl-NH

12d isobutyl-NH

13d isobutyl-NH

12e tetrahydroisoquinolin-2-yl

13e tetrahydroisoquinolin-2-yl

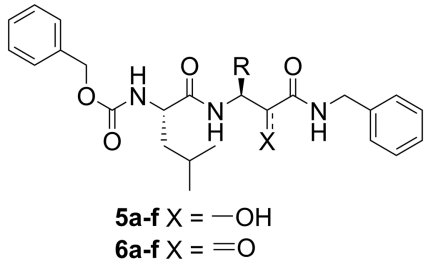

$\begin{array}{cc}\mathrm{C}_{50}(\mu \mathrm{M}) \mathrm{PGPH}(\beta 1) & \mathrm{IC}_{50}(\mu \mathrm{M}) \mathrm{T}-\mathrm{L}(\beta 2) \\ 1.45 \pm 0.31 & 4.59 \pm 0.06 \\ 0.73 \pm 0.01 & 0.43 \pm 0.01 \\ 17.82 \pm 0.90 & >100\end{array}$

$>100$

$82.36 \pm 6.72$

$>100$

$50.11 \pm 3.84$

$>100$

$73.22 \pm 5.91$

$53.15 \pm 4.27$

$89.47 \pm 8.17$

$30.57 \pm 2.76$

$15.45 \pm 1.21$

$20.44 \pm 1.76$

$1.09 \pm 0.12$

$>100$
$11.5 \pm 0.81$
$>100$
$0.56 \pm 0.02$
$>100$
$57.5 \pm 4.06$
$>100$
$5.9 \pm 0.32$
$>100$
$>100$

$57.98 \pm 4.38$

$17.61 \pm 1.18$

$51.63 \pm 5.06$

$21.54 \pm 2.05$

$>100$

$>100$

$>100$

$>100$

$>100$

$2.11 \pm 0.24$

$>100$

$1.32 \pm 0.11$

$>100$

$0.59 \pm 0.01$

$>100$

$85.4 \pm 3.12$

$>100$

$>100$

$>100$

$0.43 \pm 0.03$

$>100$

$38.9 \pm 0.98$

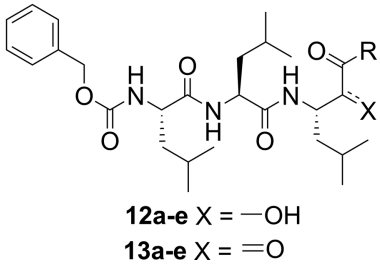

$\begin{array}{cc}\mathrm{IC}_{50}(\mu \mathrm{M}) \text { ChT-L }(\beta 5) & \mathrm{IC}_{50}(\mu \mathrm{M})^{a} \text { prolif. } \\ 0.007 \pm 0.001 & 0.82 \pm 0.03 \\ 0.014 \pm 0.001 & 0.78 \pm 0.01 \\ 0.53 \pm 0.04 & \mathrm{ND}\end{array}$

$>100$

$51.09 \pm 3.34$

$70.45 \pm 5.93$

$12.43 \pm 0.92$

$>100$

$>100$

$>100$

$>100$

$82.07 \pm 7.55$

$63.34 \pm 6.13$

$50.21 \pm 4.33$

$0.92 \pm 0.08$

$\begin{array}{ll}>100 & \text { ND } \\ 0.056 \pm 0.003 & 0.93 \pm 0.13 \\ >100 & \text { ND } \\ 0.48 \pm 0.02 & \text { ND } \\ 8.1 & \text { ND } \\ 0.007 \pm 0.001 & <0.10 \\ >100 & \text { ND } \\ 0.012 \pm 0.002 & 0.81 \pm 0.12 \\ >100 & \text { ND } \\ 0.77 \pm 0.04 & \text { ND }\end{array}$

${ }^{a} \mathrm{IC}_{50}$ proliferation values against HCT116 cells for the most potent compounds in the enzyme inhibition assays.

compounds displayed an $\mathrm{IC}_{50}$ proliferation $<1 \mu \mathrm{M}$. In particular, the compound 13c, which showed the highest activity inhibiting the $\beta 5$ subunit of the proteasome, also exerted the strongest antiproliferative effect.

Finally, to determine if this effect was associated with cell death induction, apoptosis levels were measured in HCT116 cells treated for 48 and $72 \mathrm{~h}$ with two selected compounds, i.e., 13c and 13d. The positivity to Annexin $\mathrm{V}$ and negativity to propidium iodide (P.I.) identifies early apoptotic cells while double positivity to both Annexin V and P.I., late apoptotic cells. As shown in Figure 2, 13c exhibited increased levels of late apoptotic cells already at $48 \mathrm{~h}$, and this effect was even higher at $72 \mathrm{~h}$, consistently with the lower $\mathrm{IC}_{50}$ proliferation shown in comparison to $13 \mathrm{~d}$.

Docking studies were performed for a subset of compounds (6a, 6b, 5f, 6f, and 13c) selected in respect to their biological profile, and the best binding poses of each molecule in the $\beta 1$, $\beta 2$, and $\beta 5$ binding sites were compared to those of the known $\alpha$-ketoamide tripeptide 1 a. $^{29}$ Figure $3 \mathrm{~A}$ shows compound $13 \mathrm{c}$, the most potent and selective $\beta 5$ inhibitor identified in this work, docked in the $\beta 5$ binding pocket alongside the reference compound 1a (Figure 3B). Moreover, the best binding poses for compounds $1 \mathrm{a}$ and $13 \mathrm{c}$ in the $\beta 1$ and $\beta 2$ catalytic subunits have been illustrated in Figures S1 and S2 of the Supporting Information. For each proposed binding pose, a schematic diagram of the inhibitor-protein interactions has been also supplied. For both molecules, the $\alpha$-ketoamide group was found to interact in all binding sites with the active $\mathrm{Thr}^{1}$ residue via hydrogen bonding interactions, with donoracceptor distances in the range of 2.6-3.3 $\AA$, typical of medium/strong H-bonds. Furthermore, 1a and 13c were found to be surrounded by (or interacting with) several residues which the structural analyses indicated as involved in the formation of the receptor pockets. ${ }^{5}$ For molecule 13c, the important residues $\mathrm{Thr}^{21}, \mathrm{Gly}^{47}$, and $\mathrm{His}^{108}$ were directly interacting with the ligand (Figure $3 \mathrm{~A}$ ). As a reference, for the ChT-L active center, residues $\mathrm{Thr}^{21}, \mathrm{Gly}^{47}, \mathrm{Ala}^{49}$, and $\mathrm{Ala}^{50}$ were found to be involved in the binding of known inhibitors such as Bortezomib. ${ }^{5}$ Moreover, docking results at the $\beta 5$ subunit show that the distal aromatic regions of 13c, unlike 1a, were able to establish a significant number of $\pi / \pi$ stacking and $\mathrm{CH} / \pi$ interactions with the residues $\mathrm{His}^{108}$, Trp, ${ }^{25} \mathrm{Tyr}^{170}$, and $\mathrm{Gly}^{47}$. Of note, these interactions involve both the benzyl and naphthyl terminal groups, favoring the anchorage of the molecule to the proteasome active site. In our models, a lower number of residues of the $\beta 1\left(\mathrm{Gly}^{47}\right)$ and $\beta 2\left(\mathrm{Gly}^{47}, \mathrm{Gln}^{22}\right)$ 


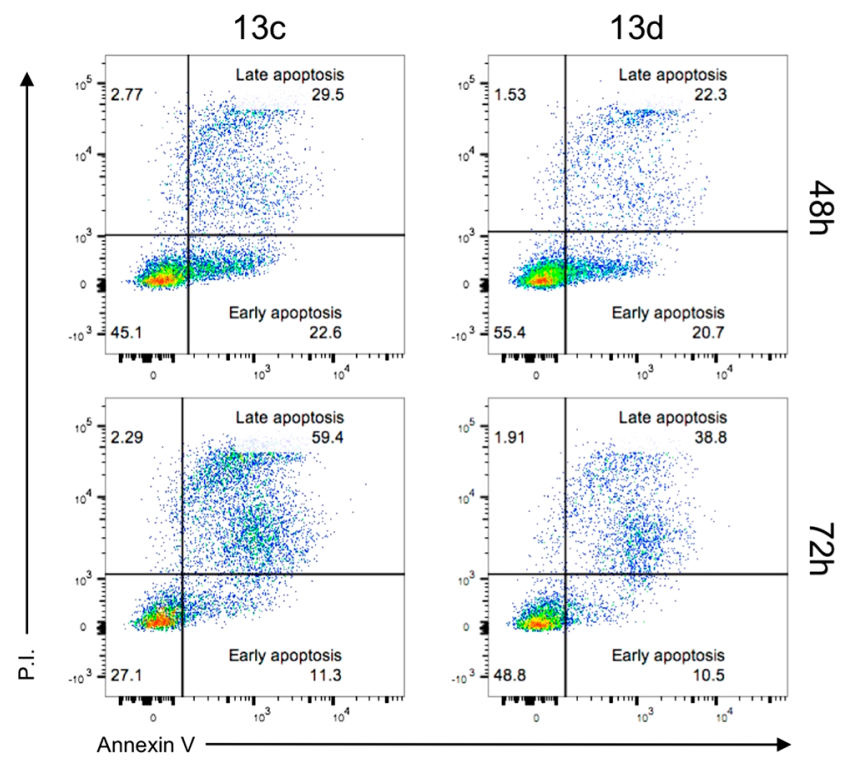

Figure 2. Effect of compounds $13 \mathrm{c}$ and $13 \mathrm{~d}$ on apoptosis induction. HCT116 tumor cells cultured for 48 or $72 \mathrm{~h}$ in the presence or absence of the indicated compounds at a concentration of $1 \mu \mathrm{M}$. Numbers in the dot plots represent percentages of cells. One representative experiment out of three is shown. subunits would make contact with the distal aromatic portions of $\mathbf{1 3 c}$, and this could account for the overall selectivity profile of the molecule.

For what is concerning the docking results obtained for the dipeptide derivative of (Figure S3) in comparison with the tripeptide analogue 1a, both molecules show their capability to fit well all of the three investigated binding sites making contact with key residues of the binding pockets. In $\beta 1$, for instance, the conserved residues are Lys, ${ }^{33} \mathrm{Thr}^{21}, \mathrm{Ser}^{118}, \mathrm{Arg}^{45}$. In $\beta 2$, it is worth mentioning the presence of the residue Cys ${ }^{118}$ of subunit $\beta 3$, which is responsible for the character of the S3 specificity pocket for the selective $\beta 2$ inhibitor Mal- $\beta$ Ala-ValArg-al. ${ }^{5}$ It is also worth noting that the tripeptide 1a, with a longer sequence by one nonpolar alkyl amino acid, is able to establish van der Waals interactions with further residues that insist around the binding pocket, something that the shorter dipeptide $\mathbf{6 f}$ presented in this work is not able to do.

The docking simulation of the other $\mathbf{6 a}, \mathbf{6 b}$, and $\mathbf{5 f}$ molecules did not give good results in comparison with those presented above, as far as the mutual $\mathrm{Thr}^{1}$-ketoamide group position is concerned. The five best poses for each molecule in the three binding pockets are reported in the Supporting Information (Figures S4-S6).

In summary, this paper describes the synthesis, biological evaluation, and docking analysis of two series of pseudodi/
A
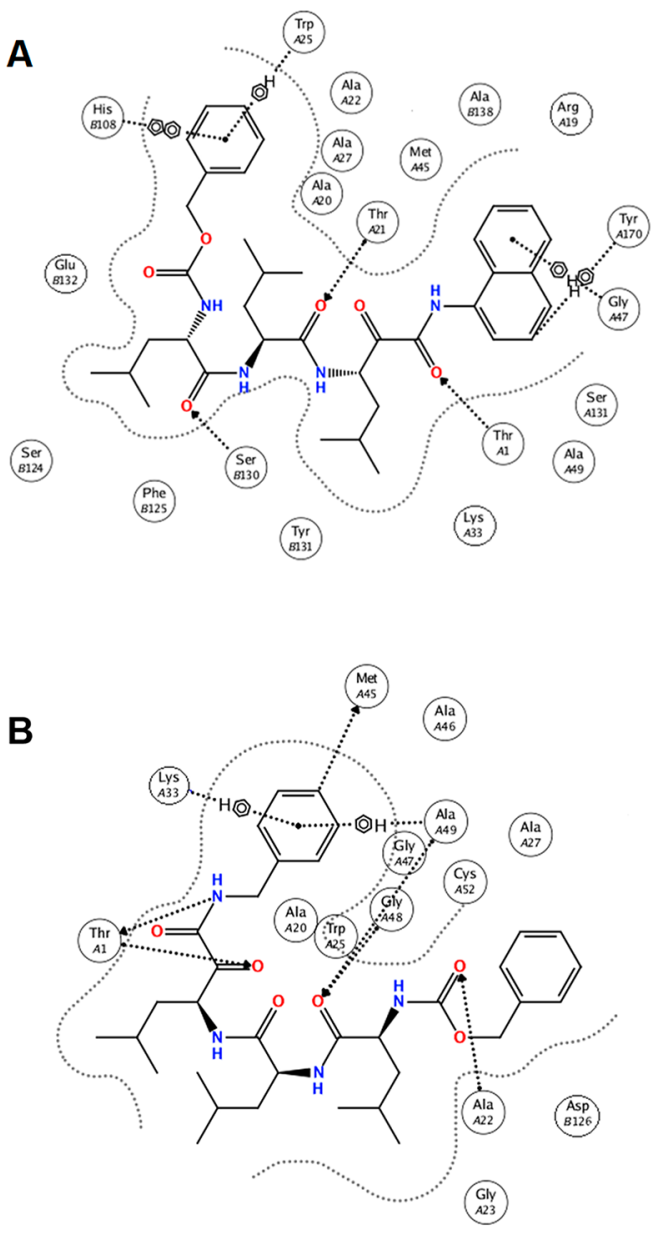
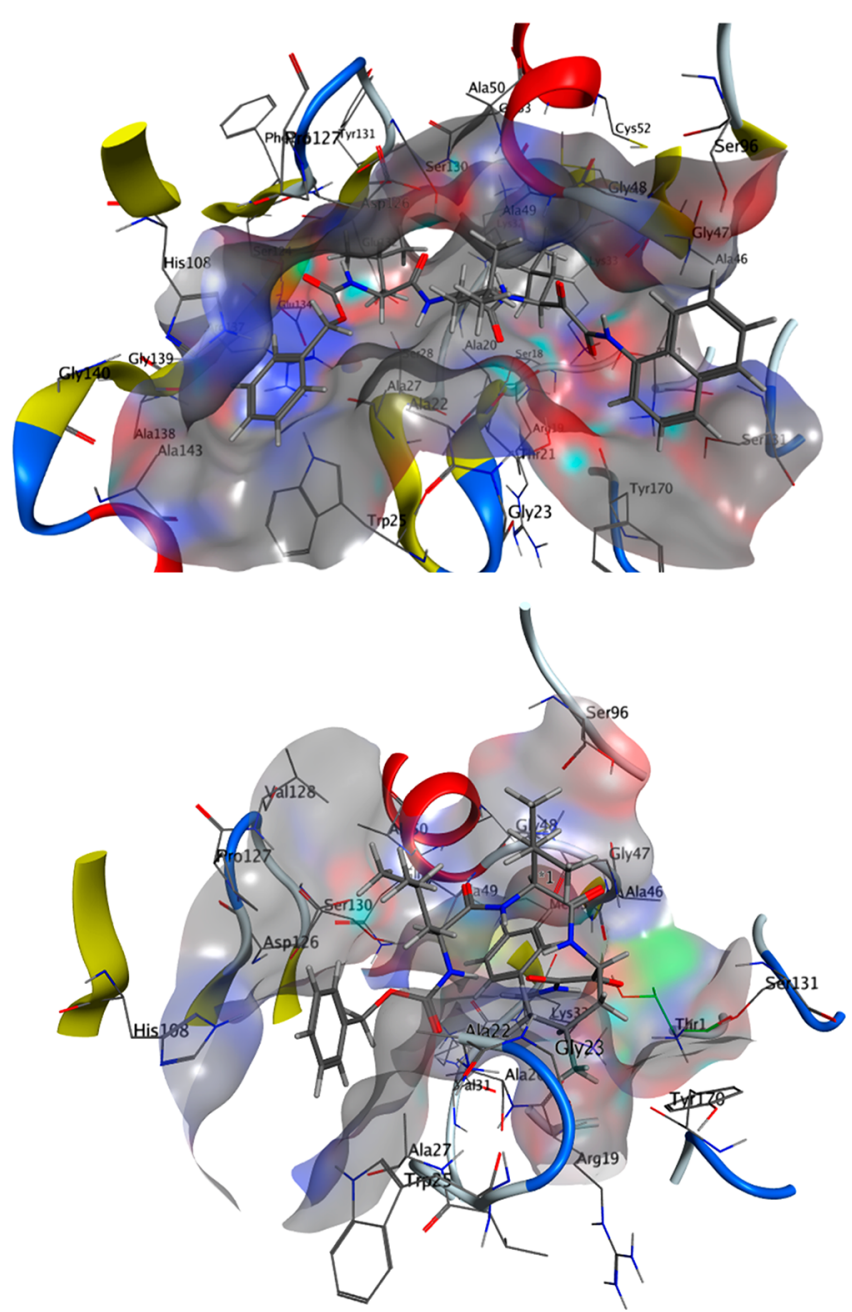

Figure 3. Molecules 13c (A) and 1a (B) in the $\beta 5$ binding pocket with a schematic diagram of the inhibitor-protein interactions. 
tripeptides as proteasome inhibitors. The entire investigated molecules feature at the C-terminal portion an $\alpha$-ketoamide as the pharmacophoric unit able to interact with and block the catalytic threonine of the active subunits of the $26 \mathrm{~S}$ proteasome. Our stepwise SAR optimization work led to the identification of $13 \mathrm{c}$ as a potent and selective inhibitor of the $\beta 5$ subunit of the $20 \mathrm{~S}$ proteasome with nanomolar potency in vitro. The compound significantly inhibited proliferation and induced apoptosis of the human colorectal carcinoma cell line HCT116, confirming the potential of $\beta 5$-selective proteasome inhibitors in cancer therapy. Recent findings would also suggest that the inhibition of the $\beta 5$ activity by selective ligands could have some therapeutic perspectives in the cardiovascular area since promoting beneficial effects in rat models of ischemia reperfusion injury. ${ }^{34}$

\section{ASSOCIATED CONTENT}

\section{S Supporting Information}

The Supporting Information is available free of charge on the ACS Publications website at DOI: 10.1021/acsmedchemlett.9b00233.

Detailed synthetic procedures, spectroscopic data and full characterizations of the described compounds, procedures for biological experiments, computational procedures, and Figures S1-S6 from the docking studies (PDF)

\section{AUTHOR INFORMATION}

\section{Corresponding Author}

*Phone: +39-532-455501. E-mail: prtdle@unife.it.

\section{ORCID $\odot$}

Delia Preti: 0000-0002-1075-3781

\section{Author Contributions}

S.P., V.A., and A.F. performed the chemical synthesis. V.F. performed and interpreted the docking study. E.G., F.N., and R.G. performed the in vitro molecular pharmacology studies. F.Z. drafted the manuscript. M.M. and D.P. oversaw and developed the project. All authors have given approval to the final version of the manuscript.

\section{Funding}

D.P. is supported by the funds FAR 2017 (Fondo di Ateneo per la Ricerca Scientifica) and FFABR 2017 (Finanziamento delle attività base di ricerca) of the University of Ferrara. M.M. is supported by the funds FAR 2017 of the University of Ferrara. The FACSCanto II was funded by Ferrara University Grant "Bando per l'acquisizione di strumenti per la ricerca di ateneo-2015".

\section{Notes}

The authors declare no competing financial interest.

\section{REFERENCES}

(1) Glickman, M. H.; Ciechanover, A. The ubiquitin-proteasome proteolytic pathway: destruction for the sake of construction. Physiol. Rev. 2002, 82, 373-428.

(2) Ciechanover, A. Proteolysis: from the lysosome to ubiquitin and the proteasome. Nat. Rev. Mol. Cell Biol. 2005, 6, 79-87.

(3) Finley, D. Recognition and processing of ubiquitin-protein conjugates by the proteasome. Annu. Rev. Biochem. 2009, 78, 477513.

(4) Groll, M.; Heinemeyer, W.; Jager, S.; Ullrich, T.; Bochtler, M.; Wolf, D. H.; Huber, R. The catalytic sites of $20 \mathrm{~S}$ proteasomes and their role in subunit maturation: a mutational and crystallographic study. Proc. Natl. Acad. Sci. U. S. A. 1999, 96, 10976-10983.

(5) Borissenko, L.; Groll, M. 20S proteasome and its inhibitors: crystallographic knowledge for drug development. Chem. Rev. 2007, 107, 687-717.

(6) Sijts, E. J.; Kloetzel, P. M. The role of the proteasome in the generation of MHC class I ligands and immune responses. Cell. Mol. Life Sci. 2011, 68, 1491-1502.

(7) Kisselev, A. F.; Van der Linden, W. A.; Overkleeft, H. S. Proteasome inhibitors: an expanding army attacking a unique target. Chem. Biol. 2012, 19, 99-115.

(8) Groll, M.; Huber, R.; Moroder, L. The persisting challenge of selective and specific proteasome inhibition. J. Pept. Sci. 2009, 15, 5866.

(9) Micale, N.; Scarbaci, K.; Troiano, V.; Ettari, R.; Grasso, S.; Zappalà, M. Peptide-based proteasome inhibitors in anticancer drug design. Med. Res. Rev. 2014, 34, 1001-1069.

(10) Moreau, P.; Richardson, P. G.; Cavo, M.; Orlowski, R. Z.; San Miguel, J. F.; Palumbo, A.; Harousseau, J. L. Proteasome inhibitors in multiple myeloma: 10 years later. Blood 2012, 120, 947-959.

(11) Adams, J. The development of proteasome inhibitors as anticancer drugs. Cancer Cell 2004, 5, 417-421.

(12) Moreau, P. The emerging role of carfilzomib combination therapy in the management of multiple myeloma. Expert Rev. Hematol. 2014, 7, 265-290.

(13) Shirley, M. Ixazomib: first global approval. Drugs 2016, 76, 405-411.

(14) Allegra, A.; Alonci, A.; Gerace, D.; Russo, S.; Innao, V.; Calabrò, L.; Musolino, C. New orally active proteasome inhibitors in multiple myeloma. Leuk. Res. 2014, 38, 1-9.

(15) Park, J. E.; Miller, Z.; Jun, Y.; Lee, W.; Kim, K. B. Nextgeneration proteasome inhibitors for cancer therapy. Transl Res. 2018, 198, 1-16.

(16) Gozzetti, A.; Papini, G.; Candi, V.; Brambilla, C. Z.; Sirianni, S.; Bocchia, M. Second generation proteasome inhibitors in multiple myeloma. Anti-Cancer Agents Med. Chem. 2017, 17, 920-926.

(17) Marastoni, M.; Baldisserotto, A.; Canella, A.; Gavioli, R.; De Risi, C.; Pollini, G. P.; Tomatis, R. Arecoline tripeptide inhibitors of proteasome. J. Med. Chem. 2004, 47, 1587-1590.

(18) Baldisserotto, A.; Ferretti, V.; Destro, F.; Franceschini, C.; Marastoni, M.; Gavioli, R.; Tomatis, R. Alpha,beta-unsaturated Nacylpyrrole peptidyl derivatives: new proteasome inhibitors. J. Med. Chem. 2010, 53, 6511-6515.

(19) Franceschini, C.; Trapella, C.; Calia, R.; Scotti, A.; Sforza, F.; Gavioli, R.; Marastoni, M. C-terminal trans,trans-muconic acid ethyl ester partial retro-inversopseudopeptides as proteasome inhibitors. J. Enzyme Inhib. Med. Chem. 2013, 28, 1034-1039.

(20) Scotti, A.; Trapella, C.; Ferretti, V.; Gallerani, E.; Gavioli, R.; Marastoni, M. Studies of C-terminal naphthoquinone dipeptides as $20 S$ proteasome inhibitors. J. Enzyme Inhib. Med. Chem. 2016, 3, 456-463.

(21) Marastoni, M.; Trapella, C.; Scotti, A.; Fantinati, A.; Ferretti, V.; Marzola, E.; Eleonora, G.; Gavioli, R.; Preti, D. Naphthoquinone aminoacid derivatives, synthesis and biological activity as proteasome inhibitors. J. Enzyme Inhib. Med. Chem. 2017, 32, 865-877.

(22) Chang, K. O.; Kim, Y.; Groutas, W. C.; Hua, D.; Saif, L. J. Broad-spectrum antivirals against $3 C$ or $3 C$-like proteases of picornaviruslike supercluster: picornaviruses, caliciviruses and coronaviruses. $\mathrm{u}, \mathrm{S}$, Patent Application 20140243341, August 28, 2014.

(23) Dondapati, J. S.; Godi, S.; Babu, A. P. QSAR studies on peptide alpha-ketoamides and alpha-ketohydroxamate derivatives as calpain I inhibitors. J. Enzyme Inhib. Med. Chem. 2008, 23, 757-762.

(24) Koguchi, Y.; Kohno, J.; Nishio, M.; Takahashi, K.; Okuda, T.; Ohnuki, T.; Komatsubara, S. TMC-95A, B, C, and D, novel proteasome inhibitors produced by Apiospora montagnei Sacc. TC 1093. Taxonomy, production, isolation, and biological activities. J. Antibiot. 2000, 53 (53), 105-109. 
(25) De Risi, C.; Pollini, G. P.; Zanirato, V. Recent developments in general methodologies for the synthesis of $\alpha$-ketoamides. Chem. Rev. 2016, 116, 3241-3305.

(26) Lynch, S. M.; Narayanan, A.; Steiner, S. Ketoamide immunoproteasome inhibitors. World Patent WO 2014056748, April 17, 2014.

(27) Stein, M. L.; Cui, H.; Beck, P.; Dubiella, C.; Voss, C.; Krüger, A.; Schmidt, B.; Groll, M. Systematic comparison of peptidic proteasome inhibitors highlights the $\alpha$-ketoamide electrophile as an auspicious reversible lead motif. Angew. Chem., Int. Ed. 2014, 53, 1679-1683.

(28) Voss, C.; Scholz, C.; Knorr, S.; Beck, P.; Stein, M. L.; Zall, A.; Kuckelkorn, U.; Kloetzel, P. M.; Groll, M.; Hamacher, K.; Schmidt, B. $\alpha$-Keto phenylamides as P1'-extended proteasome inhibitors. ChemMedChem 2014, 9, 2557-2564.

(29) Braun, H. A.; Umbreen, S.; Groll, M.; Kuckelkorn, U.; Mlynarczuk, I.; Wigand, M. E.; Drung, I.; Kloetzel, P. M.; Schmidt, B. Tripeptide mimetics inhibit the $20 \mathrm{~S}$ proteasome by covalent bonding to the active threonines. J. Biol. Chem. 2005, 280, 28394-23401.

(30) Fehrentz, J. A.; Castro, B. An efficient synthesis of optically active $\alpha$-(t-butoxycarbonylamino)-aldehydes from $\alpha$-amino acids. Synthesis 1983, 1983 (8), 676-678.

(31) DeMattei, J. A.; Leanna, M. R.; Li, W.; Nichols, P. J.; Rasmussen, M. W.; Morton, H. E. An Efficient Synthesis of the Taxane-Derived Anticancer Agent ABT-271. J. Org. Chem. 2001, 66, 3330-3337.

(32) Hansen, M. B.; Nielsen, S. E.; Berg, K. Re-examination and further development of a precise and rapid dye method for measuring cell growth/cell kill. J. Immunol. Methods 1989, 119, 203-210.

(33) Lee, D. H.; Goldberg, A. L. Proteasome inhibitors: valuable new tools for cell biologists. Trends Cell Biol. 1998, 8, 397-403.

(34) Sanchez, G.; Berrios, D.; Olmedo, I.; Pezoa, J.; Riquelme, J. A.; Montecinos, L.; Pedrozo, Z.; Donoso, P. Activation of chymotrypsinlike activity of the proteasome during ischemia induces myocardial dysfunction and death. PLoS One 2016, 11 (8), e0161068. 